\title{
Can a Cognitive-Behavioral Group-Therapy Training Program for the Treatment of Child Sexual Abuse Reduce Levels of Burnout and Job-Strain in Trainees? Initial Evidence of a Brazilian Model ${ }^{1}$
}

\author{
Bruno Figueiredo Damásio ${ }^{2}$ \\ Universidade Federal do Rio de Janeiro, \\ Rio de Janeiro-RJ, Brazil \\ Clarissa Pinto Pizarro de Freitas \\ Universidade Federal do Rio Grande \\ do Sul, Porto Alegre-RS, Brazil
}

\author{
Luísa Fernanda Habigzang \\ Pontifícia Universidade Católica do Rio \\ Grande do Sul, Porto Alegre-RS, Brazil \\ Sílvia Helena Koller \\ Universidade Federal do Rio Grande \\ do Sul, Porto Alegre-RS, Brazil
}

\begin{abstract}
This study evaluated the extent to which a professional training program of an evidence-based intervention for the treatment of child and adolescent victims of sexual abuse could reduce strain and burnout levels in trainees. Participants were 30 psychologists, 19 of whom composed the experimental group (G1) and 11 the comparison group (G2). Data collection occurred before and after the training. The results showed that the 'work demand' increased for G1 and remained stable for G2, whereas the 'control at work' remained stable for G1 while decreasing for G2. Regarding burnout levels, there was a decrease in depersonalization and stabilization in the levels of emotional exhaustion and reduced professional efficacy for G1, whereas for G2, all the burnout indicators significantly increased. These results partially support the perspective that the training program would have an indirect protective effect on the occupational psychopathology levels of the trainees.
\end{abstract}

Keywords: professional education, occupational stress, occupational health, sexual abuse, stress

\section{Pode um Programa de Treinamento em Grupoterapia Cognitivo-Comportamental Para o Tratamento de Abuso Sexual Infantil Reduzir os Níveis de Burnout e Estresse no Trabalho dos Treinandos? Evidências Iniciais de um Modelo Brasileiro}

\begin{abstract}
Resumo: Este estudo avaliou em que medida um treinamento profissional em uma intervenção empiricamente-baseada voltada para o tratamento de crianças e adolescentes vítimas de violência sexual poderia reduzir os níveis de tensão ocupacional e burnout dos profissionais capacitados. Os participantes foram 30 psicólogos, sendo que 19 compuseram o grupo experimental (G1) e 11 o grupo de comparação (G2). A coleta de dados ocorreu antes e depois da capacitação. Os resultados mostraram que os níveis de demanda ocupacional aumentaram para G1 e se mantiveram estáveis para G2. Em relação aos níveis de burnout, houve redução da despersonalização e estabilização nos níveis de exaustão emocional e de baixa eficácia profissional para G1, enquanto que para G2 todos os indicadores aumentaram. Os resultados suportam parcialmente a hipótese que o treinamento profissional pode apresentar um efeito protetor indireto nos níveis de psicopatologia ocupacional dos profissionais capacitados.
\end{abstract}

Palavras-chave: formação profissional, estresse ocupacional, saúde ocupacional, abuso sexual, estresse

\section{¿Puede un Programa de Formación en Grupoterapia Cognitivo-Conductual Para el Tratamiento del Abuso Sexual Infantil Reducir los Niveles de Burnout y Estrés en el Trabajo de los Cursillistas? Evidencias Iniciales de un Modelo Brasileño}

\begin{abstract}
Resumen: Este estudio evaluó hasta qué punto un entrenamiento profesional para uso de una intervención empíricamente basada para el tratamiento de niños y adolescentes víctimas de abuso sexual podría reducir los niveles de tensión laboral y burnout de los profesionales capacitados. Participaron 30 psicólogos, 19 en el grupo experimental (G1) y 11 en el grupo de comparación (G2). Los datos fueran recolectados antes y después del entrenamiento. Los resultados mostraron que los niveles de demanda ocupacional aumentaron en G1 y siguieron estables en G2. Respecto a los niveles de burnout, se observó reducción en la despersonalización y estabilización en los niveles de agotamiento emocional y de baja eficacia profesional en G1 mientras que, en $\mathrm{G} 2$, todos los indicadores aumentaron. Los resultados apoyan parcialmente la perspectiva que el programa de entrenamiento puede presentar un efecto protector indirecto en los niveles de psicopatología ocupacional de los profesionales capacitados.
\end{abstract}

Palabras clave: formación profesional, estrés ocupacional, salud ocupacional, abuso sexual, estrés

\footnotetext{
1 Paper derived from the master's thesis by the first author, under the supervision of the fourth author, defended in 2011, in the Psychology Graduate Program of the Universidade Federal do Rio Grande do Sul.

Support: National Council for Scientific and Technological Development (CNPq).

2 Correspondence address:

Bruno Figueiredo Damásio. Universidade Federal do Rio de Janeiro. Instituto de Psicologia. Departamento de Psicometria. Avenida Pasteur, 250. CEP 22290-902. Rio de Janeiro-RJ, Brazil. E-mail: brunofd.psi@gmail.com
}

Psychologists work in several areas as agents of change for individuals, groups, and/or organizations. The important tasks executed by these professionals require corresponding levels of responsibility and technical capabilities. In some cases, psychologists work with complex problems, such as sexual abuse, which require a broad operating strategy, 
including psychological, familial, and social interventions. Furthermore, the knowledge and involvement of other professionals, such as legal and social workers, is required, aiming to ensure more holistic protection for the victim.

Referring to the attendance of the victims of sexual abuse (SA), it has been observed that psychologists face difficulties both in making denunciations (because of legal and ethical implications), as well as in providing effective psychological accompaniment, due to lack of knowledge on the theme and lack of technical ability (Saywitz, Mannarino, Berliner, \& Cohen, 2000). In Brazil, there is still a severe lack of professional preparation to deal with this phenomenon. The inability to recognize evident signs in victimized children, the ignorance of SA dynamics, and the difficulties in observing risk and protective factors are some of the aspects reported (Freitas \& Habigzang, 2013; Habigzang, Koller, Azevedo, \& Machado, 2005). Research conducted by the Brazilian Federal Council of Psychology (Conselho Federal de Psicologia [CFP], 2009) shows that one third of the professionals employed in the public services related to sexual violence stated that they were not able to adequately deal with cases of sexual violence.

This perceived inability constitutes stressors and risk factors for the development of burnout (Emery, Wade, \& McLean, 2009). These relationships may be comprehended based on the demand-control theory (Karasek et al., 1998) and on theories explaining burnout syndrome (Maslach \& Jackson, 1981; Maslach \& Leiter, 2008), which report that the health of workers (in terms of occupational health) partially depends on their abilities to cope with the demands of their work.

The Demand-Control Model postulates that job strain is derived from the relationship between the demand and control at work. The "demand" variable incorporates aspects such as demand levels, time and pressure of deadlines, and required concentration levels. In turn, the "control" variable incorporates aspects that influence the making of decisions decision authority and skill discretion (Karasek et al., 1998).

Burnout refers to a psychological syndrome which predominantly affects social and healthcare workers who have intense social contact and caring relationships with other individuals (Awa, Plaumann, \& Walter, 2010). This syndrome, of a purely occupational nature, is characterized by: (a) the predominance of emotional dysphoric symptoms, such as emotional exhaustion and fatigue; (b) the predominance of emotional and behavioral symptoms rather than physical symptoms; (c) symptoms related to the occupational setting; (d) manifestations of symptoms in people with no diagnosis of other psychological disorders; and (e) a gradual reduction in occupational performance (Maslach \& Leiter, 2008).

Although there are various definitions of burnout among researchers, there is a strong consensus toward the dimensions that encapsulate this construct, i.e.: (a) emotional exhaustion, (b) depersonalization, and (c) reduced professional efficacy.
Emotional exhaustion represents the individual aspect of the syndrome. It relates to the perception of being overloaded and having reduced coping strategies to deal with the job demands (Demerouti, Mostert, \& Bakker, 2010; Maslach \& Leiter, 2008). Depersonalization refers to the interpersonal dimension of the syndrome. It is characterized by negative, insensitive and individualistic attitudes to other people. This cynical attitude toward job social relationships is comprehended as a cognitive strategy to help cope with the exhaustive demand of the work (Demerouti et al., 2010; Schaufeli \& Salanova, 2014). Finally, reduced professional efficacy represents the self-evaluation dimension of burnout, and is characterized by intense feelings of incompetence, low personal fulfillment, and reduced productivity at work (Maslach \& Leiter, 2008; Schaufeli \& Salanova, 2014).

Among the three dimensions, emotional exhaustion is the most characteristic of burnout, however, it cannot solely characterize burnout, as this symptom is also related to other occupational psychopathology, such as job stress (Silva, Damásio, Melo, \& Aquino, 2008). Professionals affected by this syndrome present a gradual decrease in occupational performance and psychological health (Schaufeli \& Salanova, 2014). Thus, burnout is related to several negative responses toward the work, such as occupational dissatisfaction, low organizational commitment, and absenteeism, among others (Demerouti et al., 2010).

Due to the impact of burnout on the personal and organizational environment, several intervention programs have been developed aiming to prevent and reduce burnout symptoms. These programs can be directed toward the individual, organization, community, or simultaneously toward personal and organizational factors (Awa et al., 2010; Carlotto, 2010). Interventions directed toward professionals usually aim to strengthen the abilities of the workers for coping with high levels of demand and stress, and include professional training, relaxation exercises, and increased social support. Normally, the programs directed toward organizations promote changes in work procedures to decrease job demand, increase job control, and empower professionals, such as flexibility of shifts, banked hours, and participation in decision making. Community-directed interventions aim to create partnerships between institutions and the community, through information campaigns that clarify the roles of professionals and highlighting their importance.

There is accumulating evidence for the effectiveness of person-directed interventions (Awa et al., 2010; Parker, Martin, Colmar, \& Liem, 2012). Likewise, professional training has been indicated as a protective factor against the development of burnout among professionals engaged in the care of victims of sexual violence (Coles, Dartnall, \& Astbury, 2013). In order for psychologists to be able to cope with the demands related to SA, a training program was designed to instruct professionals in the use of evidencedbased cognitive behavioral group therapy for working with 
child and adolescent victims of sexual abuse (TPEB-SA). Beyond investigating the cognitive-behavioral techniques, we were also interested in evaluating the extent to which this training program would indirectly benefit the professionals by reducing job stressors and by enhancing job skills. Given these aspects, the present study aimed to evaluate to what extent TPEB-SA could reduce the burnout levels and job strain in trainees, and increase their job control.

\section{Method}

The impact evaluation was performed through a quasiexperimental design (Robson, 1993) with a pre- (T1) and post-test (T2) in the experimental (G1) and comparison groups (G2). The G1 group was composed of the participants submitted to the TPEB-SA. The G2 group consisted of professionals who had not registered on the course.

\section{Participants}

The study sample initially consisted of 47 psychologists from 22 different municipalities of the state of Rio Grande do Sul. From the total, 28 participated in the TPEB-SA (G1) and 19 did not. The study's final sample was composed of 30 professionals, 19 of them in G1 and 11 in G2. During the TPEB-SA, two G1 participants dropped out due to incompatible schedules. The loss of the other G1 participants $(n=7)$ occurred because the participants did not attend on the day scheduled for the post-test, despite having participated in the training program. For G2, the dropouts resulted from difficulties in locating the participants after the six month period $(n=5)$, and due to explicit non-interest in participating in the second phase of the study $(n=4)$.

Regarding the participants of G1, 84.5\% were female, the mean age was 36.9 years $(S D=8.80)$, the mean of the total amount of time in the profession was 4.5 years $(S D=5.68$; range from three months to 20 years), the mean time in the current job was 3.8 years $(S D=4.6$; range from three months to 20 years), the mean weekly work load was 30.3 hours ( $S D$ $=9.5$ ), and $57.9 \%$ had completed a higher education course. Referring to G2, the sample was constituted only by female participants, the mean age was 35.0 years $(S D=6.5)$, the mean of the total amount of time in the profession was 9.3 years $(S D=5.9$; range from two months to 23 years), the mean time in the current job was 3.7 years $(S D=3.7$; range from six months to 10 years), the mean weekly work load was 30.3 hours $(S D=9.5)$, and $36.4 \%$ had completed a higher education course.

\section{Instruments}

Sociodemographic questionnaire. This instrument was used for gathering information such as gender, age, education levels and employment characteristics.

Job Content Questionnaire - JCQ (Karasek et al., 1998, adapted by Araújo \& Karasek, 2008). The JCQ evaluates the levels of demand, control (decision authority; skill discretion), and social support. The Brazilian adaptation presented adequate alpha coefficients. The results obtained were: work control, $\alpha=.65$ (decision authority: $\alpha=.69$; skill discretion: $\alpha=.65$ ); psychological demand, $\alpha=.66$; social support, $\alpha=.71$ (work colleague support, $\alpha=.69$; supervisor support, $\alpha=.79$ ); and physical demand, $\alpha=.76$. In this sample the values of internal consistency were: work control, $\alpha=.62$ (decision authority: $\alpha=.59$; skill discretion: $\alpha=.54$ ); psychological demand, $\alpha=.55$; social support, $\alpha=.80$ (work colleague support, $\alpha=.75$; supervisor support, $\alpha=.95$ ); and physical demand, $\alpha=.76$.

Maslach Burnout Inventory - MBI (Maslach \& Jackson, 1981, adapted by Lautert, 1995). The MBI is used to evaluate burnout levels in workers. In the Brazilian validation study, the scale obtained the following results: $\alpha=.86$ for the emotional exhaustion factor; $\alpha=.69$ for the depersonalization factor; and $\alpha=.76$ for reduced professional efficacy. For this study, alpha reliability was: $\alpha=.86$ for the emotional exhaustion factor; $\alpha=.66$ for the depersonalization factor; and $\alpha=.74$ for reduced professional efficacy.

\section{Procedure}

The TPEB-SA was offered to psychologists performing psychological accompaniment for child and adolescent victims of SA in public institutions of the state of Rio Grande do Sul. The main objectives of the TPEB-SA were: (a) to investigate conceptual aspects of sexual violence such as definitions, dynamics and developmental consequences; (b) to facilitate a psychological evaluation model using interview protocols and psychological instruments; and (c) to train the professionals in an evidenced-based cognitive behavioral group therapy model for psychological intervention (Habigzang et al., 2009). The referred model consists of 16 structured weekly sessions, with a total duration of four months. Studies evaluating the effectiveness of this intervention (Habigzang, Damásio, \& Koller, 2013; Habigzang et al., 2009) presented significant results in reducing posttraumatic stress disorder, depression, and anxiety in child and adolescent victims of SA. Longitudinal analyses also revealed that the therapeutic effects lasted from six to 12 months after the treatment ended.

The TPEB-SA consisted of ten monthly modules, each lasting an average of five hours, with a total duration of 50 hours. Of these modules, six consisted of theoretical and practical aspects while four were for supervising the professionals implementing group therapy in their municipalities after the instructional process (for more information on the training program, see: Freitas \& Habigzang, 2014; Habigzang \& Koller, 2011).

Data collection. Data collection occurred before and after the training program. The pre-test was applied to G1 after an initial interview, and the post-test was performed at the end of the sixth training module. The G2 participants were invited to contribute to the research after the training 
registration was over, so as to make their participation in the selection process possible. These participants were contacted through the municipal health and social assistance bureaus and through the "snowball" technique (Patton, 1990) in which G1 participants indicated possible professionals for G2. The G2 participants responded to the research through a web page developed specifically for this study's objectives. The time period between applications for both groups was six months.

Data analysis. Initially, we sought to investigate data normality by employing the Kolmogorov-Smirnov and the Shapiro-Wilk tests. Due to the non-normality of the data, all inferential analyses were conducted using non-parametric tests. The Kolmogorov-Smirnov $\mathrm{Z}$ test was employed to evaluate the sociodemographic and psychological differences between the participants included in G1 and G2. For the evaluation of the longitudinal differences, Wilcoxon signed-rank tests were performed separately for each group. To comprehend the magnitude of the differences, effect sizes were calculated (Field, 2005).

\section{Ethical Considerations}

Before commencing the data collection, this study was approved by the Research Ethics Committee of the Grupo Hospitalar Conceição (GHC), of the city of Porto Alegre, Brazil (Protocol 016/2010). All ethical principles were respected throughout the study.

\section{Results}

The normality distribution of the sample was verified through the Kolmogorov-Smirnov and Shapiro-Wilk tests. The majority of the indicators presented significant results, $p<.05$, indicating the non-normality of the data. Thus, the study results were obtained through nonparametric tests.

Comparative analyses between the groups in terms of the bio-socio-demographic variables, burnout levels, and job strain were carried out during T1 (the initial research phase, when G1 was still not affected by the intervention) to verify the similarities and differences between the groups. To evaluate the impact of the training, descriptive statistics from the Maslach Burnout Inventory (MBI) and Job Content Questionnaire (JCQ) were calculated. Wilcoxon signed-rank tests were carried out, with the aim of comparing intragroup (for T1 and T2) differences in terms of burnout levels and job strain.

The sociodemographic variables were compared between groups through Kolmogorov-Smirnov $\mathrm{Z}$ tests and exact probability tests for the ordinal variables. There were no statistically relevant differences in terms of age $(Z=-0.749$, $p=.46)$, total time in current job $(Z=-0.271, p=.792)$, or weekly work load $(Z=-1.283, p=.203)$. The total length of time in the profession was greater for $\mathrm{G} 2$ when compared to $\mathrm{G} 1(Z=1.448, p=.018)$.

The psychosocial variables evaluated by the JCQ revealed significant differences between the groups. Compared to G1, G2 presented lower levels of 'skill discretion' ( $Z=1.26, p=.028)$, 'decision authority' $(Z=1.40, p=.005)$, and 'control' $(Z=1.60, p=.002)$. G2 also demonstrated higher levels of psychological demand $(Z=1.57, p=.005)$.

In terms of burnout indicators, there were no significant differences between the groups (emotional exhaustion, $Z=0.88$, $p=.24$; depersonalization, $Z=0.39, p=.82$; reduced professional efficacy, $Z=1.098, p=.98$ ). In other words, G1 participants initially presented similar burnout indexes compared to G2.

\section{Longitudinal Evaluation of Burnout Levels}

To perform a longitudinal evaluation of burnout levels, the scores obtained were evaluated at $\mathrm{T} 1$ and $\mathrm{T} 2$ for both groups separately, using the Wilcoxon signed-rank test (see Table 1). There is no cut-off point for interpreting the results (Lautert, 1995), the higher the score, the higher the burnout levels. The mean could vary from one to five in all the scales.

Table 1

Descriptive Longitudinal Statistics for Burnout Results in G1 and G2

\begin{tabular}{|c|c|c|c|c|}
\hline & & Time 1 & Time 2 & \multirow{2}{*}{ Wilcoxon Signed-rank test } \\
\hline & & $M(S D)$ & $M(S D)$ & \\
\hline \multirow[t]{2}{*}{ Emotional Exhaustion } & Experimental & $2.03(0.46)$ & $2.07(0.40)$ & -0.09 \\
\hline & Comparison & $2.43(0.66)$ & $2.70(0.71)$ & $-2.44 *$ \\
\hline \multirow[t]{2}{*}{ Depersonalization } & Experimental & $1.44(0.44)$ & $1.28(0.35)$ & $-2.29 *$ \\
\hline & Comparison & $1.38(0.39)$ & $1.51(0.42)$ & $-2.12 *$ \\
\hline \multirow[t]{2}{*}{ Reduced Professional Efficacy } & Experimental & $1.79(0.30)$ & $1.72(0.31)$ & -1.00 \\
\hline & Comparison & $2.00(0.26)$ & $2.13(0.32)$ & $-2.23 *$ \\
\hline
\end{tabular}

$* p<.05$.

In G1, the emotional exhaustion and reduced professional efficacy levels remained stable, though there was a decrease in the depersonalization levels (medium effect size, $r=-.37$ ). In G2, however, the burnout levels increased between $\mathrm{T} 1$ and $\mathrm{T} 2$ for all the evaluated indicators: emotional exhaustion (large effect size, $r=-.52$ ), depersonalization (medium effect size, $r=-.45$ ), and reduced professional efficacy (medium effect size, $r=-.47$ ). 


\section{Longitudinal Evaluation of the Demand, Control, and Social Support at Work Indicators}

The JCQ was used to evaluate the levels of demand, control (skill discretion and decision authority), and social support at work. Table 2 presents the means values and standard deviations for each of the subscales of the instrument at $\mathrm{T} 1$ and $\mathrm{T} 2$, as well as the inferential results.
For G1, the perceived levels of psychological demand at work were higher at $\mathrm{T} 2$ when compared with $\mathrm{T} 1$ (medium effect size, $r=-.33$ ), while the 'control at work' variable remained stable from T1 to T2. For G2, the level of demand at work did not present significant differences between $\mathrm{T} 1$ and T2. Conversely, the 'control at work' levels presented a significant decrease between T1 and T2 (medium effect size,

Table 2

Longitudinal Statistics of the Psychosocial Aspects of Work in G1 and G2 (JCQ)

\begin{tabular}{|c|c|c|c|c|}
\hline \multirow{2}{*}{ Dimensions } & \multirow{2}{*}{ Group } & Time 1 & Time 2 & \multirow{2}{*}{ Wilcoxon Signed-rank tes } \\
\hline & & $M(S D)$ & $M(S D)$ & \\
\hline \multirow[t]{2}{*}{ Control } & Experimental & $76.00(5.42)$ & $75.89(5.79)$ & -0.19 \\
\hline & Comparison & $70.00(7.16)$ & $66.91(5.32)$ & $-2.12 *$ \\
\hline \multirow[t]{2}{*}{ Skill discretion } & Experimental & $38.95(2.93)$ & $38.63(2.91)$ & -0.40 \\
\hline & Comparison & $36.18(3.74)$ & $34.55(2.21)$ & $-2.06^{*}$ \\
\hline \multirow[t]{2}{*}{ Decision authority } & Experimental & $37.05(3.96)$ & $37.26(4.43)$ & -0.30 \\
\hline & Comparison & $33.82(4.14)$ & $32.36(5.20)$ & -1.30 \\
\hline \multirow[t]{2}{*}{ Psychological demand } & Experimental & $28.79(3.01)$ & $31.16(4.27)$ & $-2.05^{*}$ \\
\hline & Comparison & $32.73(3.98)$ & $32.27(4.67)$ & -0.68 \\
\hline \multirow[t]{2}{*}{ Total social support } & Experimental & $26.79(6.84)$ & $27.47(8.58)$ & -0.11 \\
\hline & Comparison & $23.00(2.24)$ & $21.00(4.60)$ & -1.58 \\
\hline \multirow[t]{2}{*}{ Supervisor support } & Experimental & $14.05(6.64)$ & $14.74(7.95)$ & -0.26 \\
\hline & Comparison & $10.91(1.97)$ & $9.82(2.99)$ & -1.60 \\
\hline \multirow[t]{2}{*}{ Colleague support } & Experimental & $12.74(1.48)$ & $12.74(1.85)$ & -0.06 \\
\hline & Comparison & $12.09(0.70)$ & $11.18(2.36)$ & -1.38 \\
\hline
\end{tabular}

$* p<.05$.

$r=-.45)$, mainly due to the decrease in the 'skill discretion' indicator. The other indicators evaluated by the JCQ (social support from colleagues, social support from supervisors, and overall social support) did not present significant changes over time for either group.

\section{Correlations Between the Levels of Burnout, Demand, Control, and Social Support at Work}

To evaluate the association between the burnout and job strain indicators, Pearson's correlations were performed between the JCQ and MBI variables for all the G1 and G2 participants with only the results obtained at $\mathrm{T} 1$ (when the G1 professionals had not received the intervention). Emotional exhaustion correlated positively with demand $(r=.39 ; p<.05)$, and negatively with control $(r=-.56$, $p<.01)$ and its subscales: decision authority $(r=-.53$, $p<.05)$ and skill discretion $r=-.43, p<.05)$, and also with total social support $(r=-.38, p<.05)$. Reduced professional efficacy correlated positively with demand $(r=.36, p<.05)$, and with control $(r=-.44, p<.01)$, decision authority $(r=-.32, p<.05)$, and skill discretion $(r=-.45, p<.05)$. There were no correlations between the JCQ variables and the depersonalization levels of burnout.

\section{Discussion}

The results found in this study partially corroborate the hypothesis that the TPEB-SA could be a useful resource in improving the participant's psychological well-being. For G1, the emotional exhaustion and reduced professional efficacy indicators of burnout remained stable throughout the study while the depersonalization levels decreased significantly. In G2, all burnout indicators increased significantly between $\mathrm{T} 1$ and $\mathrm{T} 2$.

Since 'emotional exhaustion' refers to emotional and cognitive distress generally related to excessive work demands (Demerouti et al., 2010; Maslach, Schaufeli, \& Leiter, 2001), it is possible that for G1 these levels did not rise because these professionals were going through a theoretical and practical training process to help them cope with their work demands. This hypothesis is supported by the fact that the same indicator rose significantly in G2, which did not receive any intervention during the six months. Similarly, 'reduced professional efficacy', a dimension represented by feelings of incompetence, low satisfaction, and low productivity at work, did not present alterations in G1, however, increased in G2. Reduced professional efficacy at work seems to be a function of emotional exhaustion (Schaufeli \& Salanova, 2014). In 
general, an occupational situation that contributes towards emotional exhaustion also plays a part in reducing the sense of efficiency and satisfaction at work, given that emotional exhaustion tends to emerge precisely when professionals feel incapable of coping with their workload (Demerouti et al., 2010; Maslach et al., 2001).

The depersonalization decreased from $\mathrm{T} 1$ to $\mathrm{T} 2$ for G1, as expected, and increased for G2. This burnout aspect has been characterized mainly as cynicism towards interpersonal relationships in order to help manage the workload (Schaufeli \& Salanova, 2014). Emotional and cognitive distancing has been seen as a reaction related to emotional exhaustion. Viewing people as impersonal objects makes the demands more manageable (Maslach et al., 2001; Schaufeli \& Salanova, 2014). In this sense, the fact that the depersonalization levels decreased in G1 and increased in G2 seems to support the idea that the instrument proposed by the training program helped the professionals to manage their workload.

Throughout the training program, the professionals in G1 could share their histories, their positive and negative feelings towards work, and discuss and reflect on intervention strategies for different cases of child sexual abuse. The intense experience of this theme, shared by professionals from several contexts, may have contributed towards decreasing a possible feeling of indifference towards sexual abuse victims. Conversely, the professionals in G2, who did not participate in any intervention projects during those six months, did not have the same possibilities for dealing with their occupational difficulties. The sum of such factors (the theoretical and practical training and a support network amongst work colleagues) may have been an important aspect for the professionals participating in the TPEB-SA to be able to act more empathically, that is, with greater emotional and cognitive proximity with the children and adolescents that they work with on a daily basis.

In G2, the significant increase in burnout indicators emphasizes the psychosocial risks that these professionals are submitted to in their daily work. In a relatively short period of time (six months), their feelings of emotional exhaustion, reduced professional efficacy, and depersonalization increased significantly. Healthcare professionals working in institutions, especially public ones, are often submitted to inadequate working conditions (Finkler, 2011), becoming more prone to burnout when compared to autonomous professionals (Emery et al., 2009; Rupert \& Morgan, 2005).

Public health institutions in Brazil, particularly those helping victims of sexual abuse, accumulate a series of stress factors, such as increased work demands, inadequate physical structures for work, low professional autonomy, ethical difficulties in handling cases, limitations in the protection system, and others. Together these aspects lead to a high possibility of developing burnout (Emery et al., 2009).
Professionals presenting high burnout levels are, in general, negligent with important aspects of their work, harming the quality of their services and/or the care provided, becoming less effective with reduced helping abilities (Rupert $\&$ Morgan, 2005). In the case of professionals dedicated to child protection, this is especially problematic since they almost always have to confront the victims' problems in order to make responsible and efficient decisions (Stevens \& Higgins, 2002).

Regarding the aspects evaluated by the Job Content Questionnaire (JCQ), the perceived psychological demands increased for G1 between $\mathrm{T} 1$ and $\mathrm{T} 2$, while for G2 there was no significant difference between the two periods. Psychological demand, as evaluated by the JCQ, consisted of the following aspects: working quickly; working hard; accomplishing an excessive amount of work; insufficient time for accomplishing activities; and conflicting demands at work (Araújo \& Karasek, 2008). Three distinct and complementary hypotheses could explain the results found in G1: (a) it is possible that the demand increased with time for G1 because of aspects specific to their municipality; (b) these professionals may have felt more pressured by their supervisors to perform their tasks in a more effective manner since they had been trained for this; or (c) the new dynamics of the work, as proposed and demanded by the training program (development of the evidencebased group therapy, with psychological evaluations and longitudinal accompaniment of psychopathological indicators in the victimized children) may have overloaded the professionals.

The 'control at work' level, composed of the 'decision authority' and 'skill discretion' variables, did not present statistically significant differences between $\mathrm{T} 1$ and $\mathrm{T} 2$ for G1. However, these indicators decreased in G2, specifically the skill discretion. No longitudinal studies were found that evaluated the development of psychosocial aspects at work in psychologists working with child victims of sexual abuse or any other kind of demand in public health services. It is not known whether the results found - the stable levels in G1 and the decrease in skill discretion for $\mathrm{G} 2$ - are random, given the sample differences, or whether they occurred because one group went through a training process while the other one did not. However, these results seem to match the data found throughout the burnout scale (MBI). Combining these results seems to favor the hypothesis that the reality of work experienced by these professionals is, in fact, exhausting, as has already been discussed (CFP, 2009; Emery et al., 2009; Habigzang et al., 2005).

Finally, the burnout levels present significant correlations with the demand and control levels, as evaluated by the JCQ. Similar findings have been presented in the literature (Fernet, Guay, \& Senécal, 2004; Idris, O’Driscoll, $\&$ Anderson, 2011), suggesting that these connections may be important indicators to be employed in intervention projects 
aiming to reduce psychopathological levels in professionals working in public health services.

\section{Conclusion}

The present study aimed to evaluate the effects of the TPEB-SA on job strain and burnout levels through a quasiexperimental study evaluating an experimental group (G1, TPEB-SA participants) and a comparison group (G2 - nontrained participants) over a period of six months.

The results referring to burnout levels indicate a positive result with a significant decrease in depersonalization levels for G1. The reasons why only the depersonalization levels, and not those of emotional exhaustion and reduced professional efficacy, decreased for this group were not entirely understood. It is not known whether these results occurred due to the specific characteristics of the participant sample or whether the feelings of cynicism in depersonalization are more manageable. No intervention studies were found that had performed a longitudinal evaluation of burnout indicators with this category (public health professionals). This scarcity in the literature makes it difficult to interpret the results and does not allow them to be compared with those of similar studies.

Regarding job strain levels, the psychological demands perceived at work increased significantly for G1 while the levels of work control remained stable. For G2, the demand levels at work did not present significant changes between $\mathrm{T} 1$ and T2. However, the work control levels presented a significant decrease between $\mathrm{T} 1$ and $\mathrm{T} 2$, mainly due to the decrease in the 'skill discretion' variable. The obtained results seem to support the perspective of the indirect effects of the professional training program, suggesting the need for further investigations.

Although the expected effects (reduction of all burnout indicators and increased work control levels) were not completely observed, the burnout levels did increase for G2, while G1 presented stability in emotional exhaustion and job strain levels and, above all, showed a decrease in depersonalization levels. These results suggest that the TPEB-SA had, to a certain degree, an impact on the evaluated psychopathological indicators, reducing variables considered important for occupational health.

It should be emphasized that training professionals to better manage their work demands is an important aspect in increasing levels of occupational well-being. Several studies have presented an association between high occupational demand levels and occupational psychopathology (Netterstrom et al., 2008). The present study demonstrated a decrease in depersonalization levels for G1 without an increase in work control. It is plausible that the job strain and burnout levels of the participants were related to other variables that the training program did not approach, such as income, recognition at work, professional growth opportunities, support from supervisors, and others. Furthermore, child sexual abuse, the subject covered during the professional training, is just one theme that these professionals have to deal with. The training program offered was not able to fulfill all the occupational needs of the participants, which may be related to the results found in this impact evaluation study. The results of this study are therefore inconclusive.

Since the maintenance and reduction of burnout levels and work psychosocial aspects were obtained for G1 through indirect effects (i.e., there was no planned intervention for reducing burnout and increasing work control for the participants in the TPEB-SA), the findings should be interpreted carefully. Furthermore, it was not possible to investigate the duration of the results. That is, it cannot be known how long the effects will last after the end of the training program, suggesting the need for follow-up studies in order to better understand this phenomenon. The loss of participants between $\mathrm{T} 1$ and $\mathrm{T} 2$, as well as some differences between the experimental and comparison groups, may have influenced the data presented.

Although the sample size of this study can be considered small, it is emphasized that the inclusion criteria restricted the sample to psychologists working with public policies dedicated to SA. Even so, professionals from 19 municipalities were trained and evaluated, which is an important achievement. However, the findings of this study are not conclusive and need to be replicated using different and/or larger samples, with a more rigid design, such as randomized samples.

\section{References}

Araújo, T. M., \& Karasek, R. (2008). Validity and reliability of the job content questionnaire in formal and informal jobs in Brazil. Scandinavian Journal of Work, Environment \& Health Supplements, (6), 52-59. Retrieved from http://www.sjweh.fi/show_abstract.php?abstract_id=1251

Awa, W. L., Plaumann, M., \& Walter, U. (2010). Burnout prevention: A review of intervention programs. Patient Education and Counseling, 78(2), 184-190. doi:10.1016/j.pec.2009.04.008

Carlotto, M. S. (2010). Síndrome de Burnout: O estresse ocupacional do professor. Canoas, RS: ULBRA.

Coles, J., Dartnall, E., \& Astbury, J. (2013). "Preventing the pain" when working with family and sexual violence in primary care. International Journal of Family Medicine, 2013, 1-5. doi:10.1155/2013/198578

Conselho Federal de Psicologia. (2009). Serviço de proteção social a crianças e adolescentes vitimas de violência, abuso e exploração sexual e suas famílias: Referências para a atuação do psicólogo. Brasília, DF: Author.

Demerouti, E., Mostert, K., \& Bakker, A. B. (2010). Burnout and work engagement: A thorough investigation of the independency of both constructs. Journal of Occupational Health Psychology, 15(3), 209-222. doi:10.1037/a0019408 
Emery, S., Wade, T. D., \& McLean, S. (2009). Associations among therapist beliefs, personal resources and burnout in clinical psychologists. Behaviour Change, 26(2), 83-96. doi:10.1375/bech.26.2.83

Fernet, C., Guay, F., \& Senécal, C. (2004). Adjusting to job demands: The role of work selfdetermination and job control in predicting burnout. Journal of Vocational Behavior, 65(1), 39-56. doi:10.1016/S0001-8791(03)00098-8

Field, A. (2005). Discovering statistics using SPSS (2nd ed.). London, England: Sage.

Finkler, L. (2011). Avaliação de um projeto social para crianças e adolescentes em situação de rua e suas famílias (Unpublished doctoral dissertation). Universidade Federal do Rio Grande do Sul, Porto Alegre, RS.

Freitas, C. P. P., \& Habigzang, L. F. (2013). Percepções de psicólogos sobre a capacitação para intervenção com vítimas de violência sexual. Psicologia Clínica, 25(2),215-230. doi:10.1590/S0103-56652013000200013

Freitas, C. P. P., \& Habigzang, L. F. (2014). Tecnologia social de capacitação profissional para intervenção com adolescentes vítimas de violência sexual. In L. F. Habigzang, E. Diniz, \& S. H. Koller (Eds.), Trabalhando com adolescentes: Teoria e pesquisa (pp. 309-327). Porto Alegre, RS: Artmed.

Habigzang, L. F., Damásio, B. F., \& Koller, S. H. (2013). Impact evaluation of a cognitive behavioral group therapy model in Brazilian sexually abused girls. Journal of Child Sexual Abuse, 22(2), 173-190. doi:10.1080/10538712.2013.737445

Habigzang, L. F., \& Koller, S. H. (2011). Intervenção psicológica para crianças e adolescentes vítimas de violência sexual: Manual de capacitação profissional. São Paulo, SP: Casa do Psicólogo.

Habigzang, L. F., Koller, S. H, Azevedo, G. A., \& Machado, P. X. (2005). Abuso sexual infantil e dinâmica familiar: Aspectos observados em processos jurídicos. Psicologia: Teoria e Pesquisa, 21(3), 341-348. doi:10.1590/S0102-37722005000300011

Habigzang, L. F., Stroeher, F. H., Hatzenberger, R., Cunha, R. C., Ramos, M. S., \& Koller, S. H. (2009). Grupoterapia cognitivo-comportamental para crianças e adolescentes vítimas deabuso sexual. RevistadeSaúdePública, 43(Supl. 1), 70-78. doi:10.1590/S0034-89102009000800011

Idris, M. K., O'Driscoll, M. P., \& Anderson, M. H. (2011). Longitudinal mediation effects of strain on the relationships between role stressors and employees' withdrawal responses. Stress \& Health, 27(5), 403-412. doi:10.1002/smi.1392

Karasek, R., Brisson, C., Kawakami, N., Houtman, I., Bongers, P., \& Amick, B. (1998). The Job Content Questionnaire (JCQ): An instrument for internationally comparative assessments of psychosocial characteristics. Journal of Occupational Health Psychology, 3(4), 322-355. doi:10.1037/1076-8998.3.4.322
Lautert, L. (1995). O desgaste profissional do enfermeiro (Unpublished doctoral dissertation). Universidad Pontifícia de Salamanca, Salamanca, Espanha.

Maslach, C., \& Jackson, S. E. (1981). The measurement of experienced burnout. Journal of Organizational Behavior, 2(2), 99-113. doi:10.1002/job.4030020205

Maslach, C., \& Leiter, M. P. (2008). Early predictors of job burnout and engagement. Journal of Applied Psychology, 93(3), 498-512. doi:10.1037/0021-9010.93.3.498

Maslach, C., Schaufeli, W. B., \& Leiter, M. P. (2001). Job burnout. Annual Review of Psychology, 52, 397-422. doi:10.1146/annurev.psych.52.1.397

Netterstrom, B., Conrad, N., Bech, P., Fink, P., Olsen, O., Rugulies, R., \& Stansfed, S. (2008). The relation between work-related psychosocial factors and the development of depression. Epidemiologic Reviews, 30(1), 118-132. doi:10.1093/epirev/mxn004

Parker, P. D., Martin, A. J., Colmar, S., \& Liem, G. A. (2012). Teachers' workplace well-being: Exploring a process model of goal orientation, coping behavior, engagement, and burnout. Teaching and Teacher Education, 28(4), 503-513. doi:10.1016/j.tate.2012.01.001

Patton, M. Q. (1990). Qualitative evaluation and research methods (2nd ed.). Newbury Park, CA: Sage.

Robson, C. (1993). Real world research. Oxford, United Kingdom: Blackwell.

Rupert, P. A. \& Morgan, D. J. (2005). Work setting and burnout among professional psychologists. Professional Psychology: Research and Practice, 36(5), 544-550. doi:10.1037/0735-7028.36.5.544

Saywitz, K. J., Mannarino, A. P., Berliner, L., \& Cohen, J. A. (2000). Treatment for sexually abused children and adolescents. American Psychologist, 55(9), 1040-1049. doi:10.1037/0003-066X.55.9.1040

Schaufeli, W. B., \& Salanova, M. (2014). Burnout, boredom and engagement at the workplace. In M. C. W. Peeters, J. Jonge, \& T. W. Taris (Eds.), People at work: An introduction to contemporary work psychology (pp. 293-320). Chichester, United Kingdom: Wiley-Blackwell.

Silva, J. P., Damásio, B. F., Melo, S. A., \& Aquino, T. A. A. (2008). Estresse e burnout em professores. Revista Fórum Identidades, 3, 75-83. Retrieved from http://200.17.141.110/periodicos/revista forum_identidades/revistas/ARQ_FORUM_IND_3/ SESSÄ__L_FORUM_Pg 75 83.pdf

Stevens, M., \& Higgins, D. J. (2002). The influence of risk and protective factors on burnout experienced by those who work with maltreated children. Child Abuse Review, 11(5), 313-331. doi:10.1002/car.754 
Bruno Figueiredo Damásio is a Professor of the Instituto de Psicologia, Universidade Federal do Rio de Janeiro.

Luísa Fernanda Habigzang is a Professor of the Graduate Program in Psychology of the Pontifícia Universidade Católica do Rio Grande do Sul.

Clarissa Pinto Pizarro de Freitas is a Ph.D. candidate of the Graduate Program in Psychology of the Instituto de Psicologia at the Universidade Federal do Rio Grande do Sul.

Silvia Helena Koller is a Professor of the Instituto de Psicologia at the Universidade Federal do Rio Grande do Sul.

Received: June 7, 2013

1st Revision: Mar. 1, 2014

Approved: Mar. 7, 2014

How to cite this article:

Damásio, B. F., Habigzang, L. F., Freitas, C. P. P., \& Koller, S. H. (2014). Can a cognitive-behavioral group-therapy training program for treatment of child sexual abuse reduce levels of burnout and job-strain on trainees? Initial evidence of a Brazilian model. Paidéia (Ribeirão Preto), 24(58), 233-241. doi: 10.1590/1982-43272458201411 


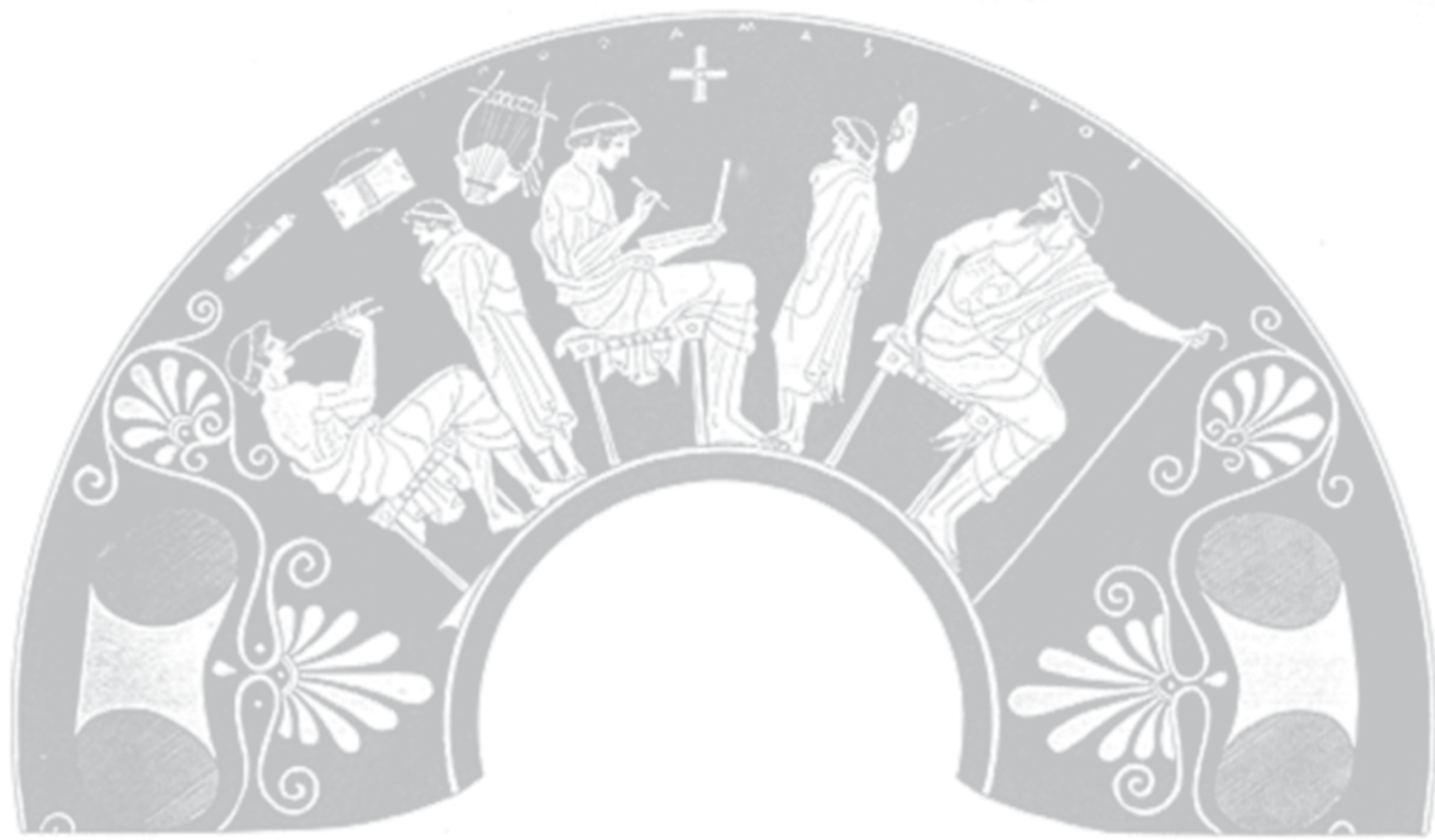

